\title{
REGIONAL PATTERNS OF CORTICAL BLOOD FLOW DISTINGUISH EXTRAVERTS FROM INTROVERTS
}

\author{
G. STENBERG ${ }^{1}$, J. RISBERG ${ }^{2}$, S. WARKENTIN ${ }^{2}$ and I. RoséN ${ }^{1}$ \\ ${ }^{1}$ Department of Clinical Neurophysiology and ${ }^{2}$ Department of Psychiatry. University of Lund. \\ S-221 85 Lund. Sweden
}

(Received 26 July 1989)

\begin{abstract}
Summary-Eysenck's hypothesis of higher cortical arousal in introverts was examined using regional cerebral blood flow measurement in 37 healthy subjects. The measurement was made at rest, using the ${ }^{133} \mathrm{Xe}$-inhalation method. Estimates of gray matter flow were obtained for 32 brain regions. There was no significant evidence of personality differences in general arousal, as measured by the mean flow level, averaged over all regions. There were. however, regional differences. An overall test of the blood flow distribution indicated different patterns of activity in introverts and extraverts. Follow-up tests attributed this to higher flow in the temporal lobes for introverts than for extraverts. Higher temporal lobe activity in introverts may be interpreted as increased functional connections between cortex and the limbic system. Related findings of personality alterations in temporal lobe epilepsy and the Klüver-Bucy syndrome support this contention
\end{abstract}

\section{INTRODUCTION}

In Eysenck's personality theory, the dimension of extraversion-introversion occupies an important role in linking cortical activity to personality (Eysenck, 1967). The key functional system, a loop connecting the ascending reticular system to the cortex, regulates the state of arousal on a continuum, ranging from sleep to full alertness. On this scale, introverts are assumed to occupy a position closer to the most alert end than the extraverts do, and from this tenet their personality characteristics are derived. Introverts are assumed to shun the external stimulation that extraverts pursue, the former because it makes them depart from the point of optimal arousal, the latter because it makes them approach it. Furthermore, the shaping influences of classical conditioning are brought to bear more forcefully on introverts, in whom learning is facilitated by greater arousal.

Empirical support has come from studies of perception, showing higher sensitivity to low-intensity stimulation in introverts (Siddle, Morrish, White \& Mangan, 1969; Stelmack \& Campbell, 1974). This has been linked to the arousal hypothesis by animal studies showing increases in perceptual efficiency during direct stimulation of the reticular formation (Fuster \& Uyeda, 1962). However, since increases in alertness may be a sufficient condition for increased sensitivity without being a necessary one, the conclusion of higher arousal in introverts is only indirect.

Both studies of electrodermal orienting reactions and of conditioning tend to find the predicted differences between extraverts and introverts only under low to moderately arousing conditions (Levey \& Martin, 1981; Stelmack, 1981). These findings have been linked to the main hypothesis by the added assumption that introverts are pushed beyond an optimum point by stressful conditions, resulting in decrements of performance and responsivity (Eysenck, 1967, 1983).

The more direct evidence, involving measures of brain activity, has proved to be equivocal. The EEG, although a demonstrably useful tool in indicating stages of the sleep-wakefulness cycle, has not convincingly demonstrated differences in arousal level between introverts and extraverts. Reviews by Gale (1983) have pointed to inconsistencies in method that may explain conflicting results, and Gale concludes that only experimental conditions inducing intermediate levels of arousal can bring out arousal differences in the predicted direction. Studies following this prescription have, however, not uniformly upheld Gale's conclusion (O'Gorman, 1984; O'Gorman \& Mallise, 1984).

An alternative measure of brain function, regional cerebral blood flow (rCBF) has been shown to reflect differences in cortical activity related to mental effort and task execution (Ingvar \& Risberg, 1965, 1967; Risberg \& Ingvar, 1973; Risberg, 1980, 1986). The coupling between blood flow and cortical activity arises because the perfusion of the brain tissue is closely regulated by its 
functional demands. The correspondence between metabolic activity and blood flow has been verified in humans by Raichle and associates (Raichle, Grubb. Gado, Eichling \& Ter-Pogossian, 1976). Indices of $\mathrm{rCBF}$ are obtained by tracing the clearance of an inert radioisotope from an array of detectors positioned around the head. The method has been used to demonstrate intra-individual differences related to perception and problem solving as well as inter-individual differences caused by brain diseases or normal ageing (Risberg, 1986).

In a study by Mathew and coworkers (Mathew, Weinman \& Barr, 1984), the rCBF method has been applied to the question of arousal differences between introverts and extraverts. In a sample of 51 women, a negative correlation between extraversion and rCBF was found, in agreement with Eysenck's theory. Correlations were approximately uniform over all brain regions examined (eight for each hemisphere), with an average of -0.36 .

The purpose of the present study was to examine the relation between extraversion and CBF, globally as well as regionally, in a sample of both men and women.

\section{METHOD}

\section{$r C B F$}

After receiving an explanation of the measurement procedure and its purpose, $S$ s were instructed to lie down and breathe through a face mask. Eyes were covered with eye pads and were to remain closed throughout the measurement. The instruction was to relax without falling asleep. The laboratory was silent except for some white noise from the recording equipment.

During $1 \mathrm{~min}$, inhalation air was mixed with the odourless and chemically inert, gamma radiating gas ${ }^{133}$ xenon. For the following $10 \mathrm{~min}, S \mathrm{~s}$ continued to breathe through the face mask, but no more xenon was supplied to the inhalation air. During this period. the washout of the gas was monitored by 32 scintillation detectors (Cerebrograph 32 C, Novo Diagnostic Systems, Denmark), arranged in a helmet and radially directed towards the centre of the head. The recorded clearance curves were submitted to bi-compartmental analysis (Obrist. Thompson, Wang \& Wilkinson, 1975), through which estimates of fast circulation (mainly gray matter flow) and slow circulation (mainly white matter flow) are obtained. All subsequent analyses are based on the fl estimate of the gray matter flow.

The arterial partial pressure of carbon dioxide $\left(\mathrm{pCO}_{2}\right)$ was estimated from capnograph recordings of end-tidal $\mathrm{CO}_{2}$ concentrations.

After the resting measurement each $S$ underwent two measurements during mental activation. The activation tasks, which included both verbal and non-verbal tests, were, however, not the same two for all $S \mathrm{~s}$ of this study. Hence only passing reference will be made to their results.

\section{Subjects}

Thirty-seven healthy volunteers participated (19 men and 18 women), in ages ranging from 21 to 61 , with an average of 34 . They were all right handed as measured by the Edinburgh Handedness Inventory. Each $S$ had undergone an interview and a general physical and neurological examination in order to exclude psychiatric illness, abuse of alcohol or drugs, hypertension, coronary and peripheral vascular disease, systemic metabolic alterations and neurological disorders. They had volunteered by responding to advertisements, and were paid for their participation.

\section{Personality measurement and personality group ditision}

Before the rCBF examination, each $S$ completed the Eysenck Personality Inventory, form B, in a Swedish translation. The EPI was preferred to the more recent EPQ, because the extraversion scale of EPI has a higher content of impulsivity items than the corresponding scale in the EPQ, in which much of this subscale has been moved to the P scale. In view of the fact that impulsivity may be an important component of physiologically based personality differences (Barratt \& Patton, 1983; Revelle, Humphreys, Simon \& Gilliland, 1980; Schalling. Edman \& Åsberg, 1983), it was thought that the arousal theory of extraversion could be tested more satisfactorily using the extraversion concept of the EPI, for which the theory was originally conceived.

Means and standard deviations of the personality scales are given in Table 1, as well as their intercorrelations. Extraversion scores are high, and neuroticism scores are low, in comparison with 
Table 1

\begin{tabular}{|c|c|c|c|c|c|}
\hline \multicolumn{3}{|c|}{ Personality variables } & \multicolumn{3}{|c|}{ Correlations } \\
\hline & Mean & SD & Neuroticism & Lie & Age \\
\hline \multicolumn{6}{|l|}{ Exiraversion } \\
\hline all & 14.80 & 3.27 & 0.03 & -0.17 & -0.30 \\
\hline men & 14.92 & 3.39 & & & \\
\hline women & 14.67 & 3.24 & & & \\
\hline \multicolumn{6}{|l|}{ Neuroticism } \\
\hline men & 5.21 & 2.84 & & & \\
\hline women & 7.08 & 2.81 & & & \\
\hline \multicolumn{6}{|l|}{ Lie } \\
\hline all & 2.35 & 1.55 & & & 0.05 \\
\hline men & 3.05 & 1.39 & & & \\
\hline women & 1.61 & 1.38 & & & \\
\hline
\end{tabular}

the Swedish standardization group averages (E: 13.03; N: 8.05), probably as a result of the selection bias involved in self-initiated participation in this type of examination.

For analyses of variance of differences between high and low extraversion $S \mathrm{~s}$, a cut-off point at 14.5 was chosen, yielding 15 introverts ( 7 men, 8 women) and 22 extraverts ( 12 men, 10 women). Tied scores made it impossible to achieve equal group sizes. The sex distribution did not differ significantly between extraversion groups $\left[\chi^{2}(1)=0.22\right.$, NS]. There were, however, age differences, with extraverts having a lower mean age $[30.8 \mathrm{vs} 38.8 \mathrm{yr} ; F(1,35)=4.78 ; P=0.04]$. For this reason, age has been entered as a covariate into ANOCOVAs wherever there was a risk of confounding effects of age with those of extraversion.

A cut-off point on the neuroticism scale was placed at 6.5, with $24 S$ s falling below (15 men, 9 women), and 13 above ( 4 men, 9 women). The sex difference was almost significant $\left[\chi^{2}(1)=3.40\right.$; $P=0.07]$, but there was no age difference $[F(1,35)=1.34 ; \mathrm{NS}]$.

\section{Data processing and statistical treatment}

In the analysis of regional flow differences, the fl flow rates were converted to distribution values by dividing the $\mathrm{fl}$ value for each detector with the average across all detectors.

Because of the risk of falsely significant results in repeated measurement ANOVAs if the sphericity assumption has been violated, the probabilities given here are those associated with multivariate analyses of variance as recommended by Vasey and Thayer (1987).

\section{RESULTS}

\section{Mean cerebral blood flow}

Mean blood flow was computed as the average of the $\mathrm{fl}$ measure across all 32 detectors. The hypothesized negative correlation between extraversion and mean flow was not obained: $r=0.10$, NS (Fig. 1). The corresponding correlations for the $N$ and $L$ scales were 0.13 and -0.30 , respectively, both non-significant.

Age has been found to correlate negatively with blood flow (Hagstadius \& Risberg, 1989), and women have been found to have higher flow rates than men (Rodriguez, Warkentin, Risberg \& Rosadini, 1988). Therefore, age, sex, and $\mathrm{pCO}_{2}$, also a possibly confounding factor (Maximilian, Prohovnik \& Risberg, 1980), were entered as independent variables along with extraversion into a multiple regression analysis. The results, presented in Table 2 , show that age and sex did indeed exert a significant influence on mean blood flow in the predicted directions, but $\mathrm{pCO}_{2}$ did not. Although $\mathrm{pCO}_{2}$ can affect cerebral blood flow strongly through hemodynamic mechanisms, its limited variability in this study did not covary with blood flow. Even after correction for these extraneous influences, extraversion did not approach a significant correlation with mean flow.

In comparison with the study by Mathew and coworkers (Mathew et al., 1984)-where a predicted negative correlation between extraversion and blood flow was observed-this sample differs by including both sexes and a wider age range. If, however, our sample is restricted to women, and age is partialled out, a correlation of -0.34 is obtained. Similarly, if the age distribution in our group of women is made to emulate that of the Mathew group ( $32.0 \pm 8.3 \mathrm{yr})$ 


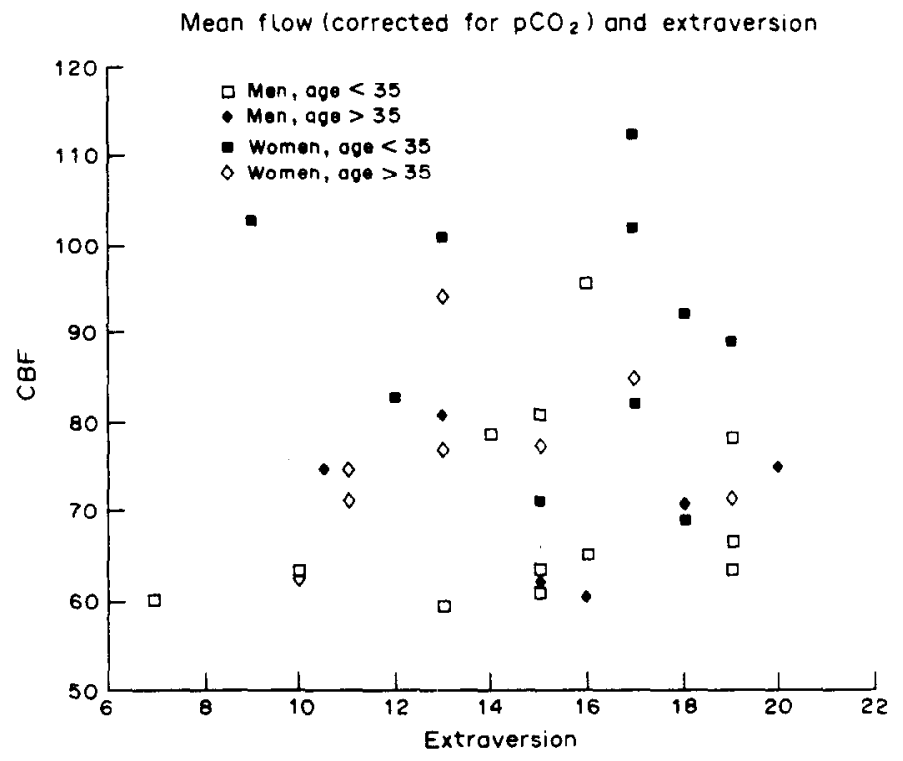

Fig. 1. Scatter plot of cerebral blood flow as a function of extraversion. Mean blood flow levels have been adjusted for $\mathrm{pCO}_{2}$ according to the formula: $\mathrm{CBF}$ corrected $=\mathrm{CBF}+2.3^{*}(40-\mathrm{pCO})$ (Maximilian et al., 1980).

by the exclusion of women over 50 , the remaining 14 women (age $29.1 \pm 6.0$ ) exhibit a correlation of -0.33 between extraversion and blood flow, again a result resembling that of the Mathew study, but not reaching significance.

\section{Regional differences}

Distribution flow values were processed in two ways: first, a repeated measures ANOVA was used to assess the overall significance of regional differences between personality groups. Secondly, analyses were performed for each detector separately and the resulting $t$-values were displayed as cortex maps.

\section{ANOVAS}

Distribution values were aggregated into five regions (frontal, temporal, central, parietal, and occipital) and were entered into a 3-way ANOVA (two extraversion groups $\times$ two hemispheres $\times$ five regions) with repeated measures on the last two factors. The main effect of hemisphere was not significant, but that of region was $[F(4,32)=76.39 ; P<0.001]$.

Moreover, the interaction of extraversion and regions was significant $[F(4.32)=3.56 ; P=0.016]$, indicating different flow distributions between introverts and extraverts (Figs 2 and 3). Follow-up tests revealed this effect to be mainly due to higher temporal flow in introverts in both hemispheres $[F(1,35)=12.79 ; P=0.001$, and still significant at the 0.01 -level after Bonferroni correction for the five regions tested]. Entering age as a covariate did not appreciably alter the extraversion $\times$ regions interaction $[F(4,31)=3.47 ; P=0.018]$. The test of the temporal regions alone also remained highly significant with age as a covariate $[F(1,34)=14.23 ; P=0.001]$. Analogously, entering sex as a covariate left both the extraversion $\times$ regions effect $[F(4,31)=3.39 ; P=0.020]$ and the temporal regions difference $[F(1,34)=12.39 ; P=0.001]$ essentially unaltered. No hemisphere differences between extraversion groups were significant.

Table 2. Mean flow (f): multiple regression analysis with age, sex, $\mathrm{pCO}_{2}$ and extraversion as predictors

\begin{tabular}{lcrrrr}
\hline Variable & Coefficient & SD error & SD coef & \multicolumn{1}{c}{1} & \multicolumn{1}{c}{$P(2$-tail $)$} \\
\hline Constant & 54.172 & 26.890 & 0.000 & 2.015 & 0.052 \\
pCO & 0.552 & 0.536 & 0.172 & 1.030 & 0.311 \\
Age & -0.474 & 0.155 & -0.470 & -3.050 & 0.005 \\
Sex & 8.989 & 3.732 & 0.396 & 2.409 & 0.022 \\
Extraversion & -0.083 & 0.535 & -0.024 & -0.156 & 0.877 \\
\hline
\end{tabular}

Coding for sex: Male $=1$. Female $=2$. 


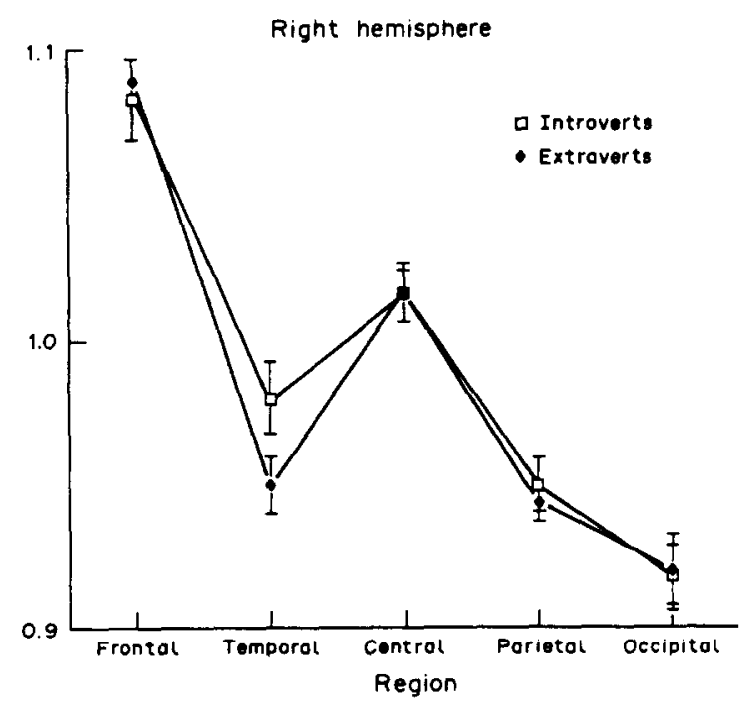

Fig. 2. Relative cerebral blood flow for extraverts and introverts in right hemisphere regions. Vertical bars indicate standard error.

A corresponding overall 3-way ANOVA was performed using neuroticism as the grouping variable. Since it did not reveal any significant effects involving neuroticism, the analysis was not continued.

t-tests

Between-groups $t$-tests evaluating group differences between extraverts and introverts were computed for each of the 32 detectors. They are illustrated in Fig. 4, in which $t$-values have been colour coded, and areas not directly covered by a detector have been assigned a value by interpolation from the four nearest neighbouring detectors, weighted by the inverse square of their distances. The highest $t$-values were associated with the detectors covering anterior temporal areas on both sides (left: 2.85 , right: 2.22 ), both of which indicate higher relative flow in introverts.

Furthermore, to adjust for age and sex, both of which affect the regional distribution as well as the overall level of blood flow, multiple regression analyses were performed for each detector, in which age, sex and extraversion were entered as independent variables. The $t$-values associated with the regression coefficients for extraversion are illustrated in Fig. 5, where colour coding and

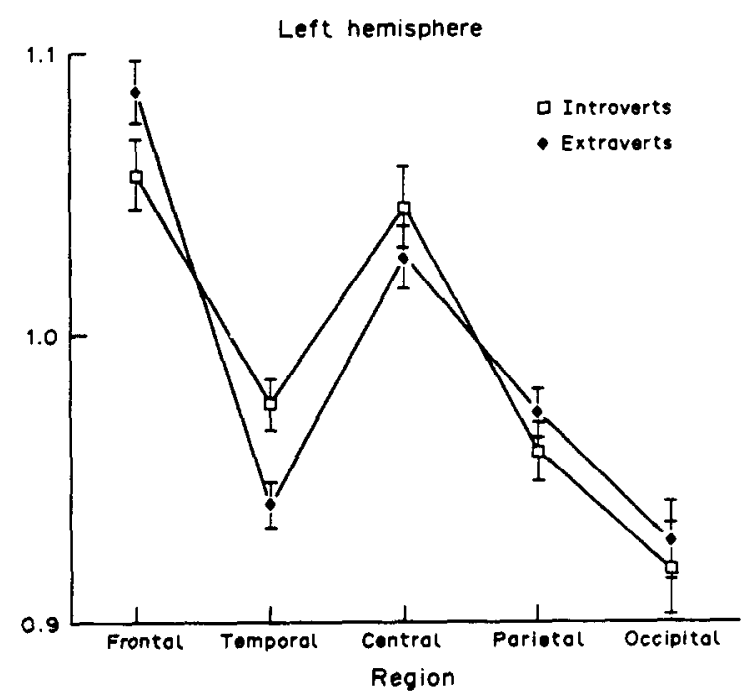

Fig. 3. Relative cerebral blood flow for extraverts and introverts in left hemisphere regions. Vertical bars indicate standard error. 
interpolation has been performed as in Fig. 4. The higher temporal flow in introverts is further accentuated. Some of what appears to be higher frontal activity in extraverts in Fig. 4. proves to be mediated by the intervening variable of age, which is negatively correlated with both extraversion and high frontal activity. A left frontal area, approximately corresponding to the area of Broca, remains, however, significantly more activated in extraverts $(P=0.04)$.

\section{Activation measurements}

Since different subsets of $S$ s underwent different activations, detailed comparisons of activation responses are not possible. However, an averaged activation measurement was computed for each $S$ as the mean of the two activations he/she did undergo. This permitted an answer to the question whether heightened alertness altered the correlations between extraversion and mean CBF. It did not. The correlation remained 0.10 (NS), a reflection of the fact that the correlation between mean resting $\mathrm{CBF}$ and mean activated $\mathrm{CBF}$ was very high (0.89). A test on distribution values in the averaged activation measurement showed higher values for introverts than for extraverts over the anterior temporal lobes $[F(1,35)=4.74 ; P=0.042]$. This difference was more marked on the right side

\section{DISCUSSION}

\section{Mean blood flow level}

The main findings of this study are the differences in the regional distribution of blood flow in the temporal lobes between extraverts and introverts, and the lack of overall differences in mean flow. The negative finding can be reconciled with Eysenck's arousal hypothesis for extraversion, only if it can be maintained either that the mean CBF value does not reflect arousal adequately, or that the experimental condition did not bring out habitual arousal differences between individuals.

Turning to the first objection, the relation between arousal and CBF level may fail to hold for interindividual comparisons, despite the amply demonstrated fact that intraindividual differences in CBF level accompany arousal changes, since other factors may generate CBF differences between individuals large enough to overwhelm those possibly caused by arousal. Of such factors, age, sex and $\mathrm{pCO}_{2}$ have been taken into account here, since they are known to produce CBF differences not easily explained as arousal differences. Efforts have been made here to disentangle their effects from those of personality, with the result that the negative finding still stands, except possibly for a homogeneous subgroup of young women.

The latter finding agrees with the result of the Mathew et al. study (1984) in which the predicted correlation between extraversion and CBF was found in a sample of young women. Since women are known to have a higher mean blood flow than men, and younger persons higher than older, selection of the demographic subgroup with the highest flow levels may reveal an underlying correlation that is present across all groups, but elsewhere obscured by factors such as subclinical vascular defects, or variations in respiratory efficiency and in the oxygen-carrying capacity of the blood. This line of reasoning leads to the conclusion that the Eysenckian hypothesis may be right, although CBF may not be the best way to test it. Since, however, this argument is based on the interpretation of non-significant results, the more conservative conclusion of no relation between extraversion and mean CBF is more solidly based in the present results.

As to the second objection, it has been proposed that only moderately arousing conditions bring out personality differences. Overly stressful conditions and anxiety may paradoxically lower cortical activity (Gur et al., 1988) as well as performance, in accordance with Yerkes-Dodson's law. Individuals with a habitually high arousal level may be more prone to this effect, thus rendering group comparisons difficult to interpret. At the other end, very relaxing conditions may invite distracting mental activity, wuch as day dreaming, again confusing the issue of personality differences.

In the resting measurement, no specific task was given, and external stimulation was kept to a minimum. On the other hand, it is well known that this measurement procedure in itself may induce some worry and discomfort, especially when a $S$ encounters it for the first time, as these $S$ s did. This effect is manifest in a drop of CBF levels in a subsequent resting measurement (Prohovnik, 


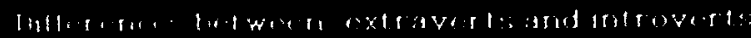

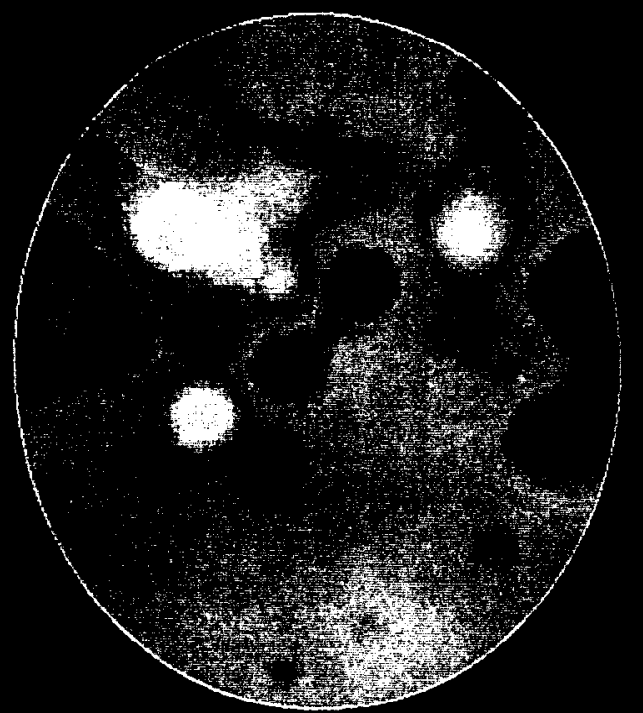

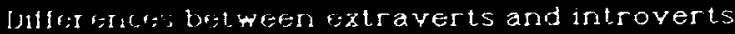

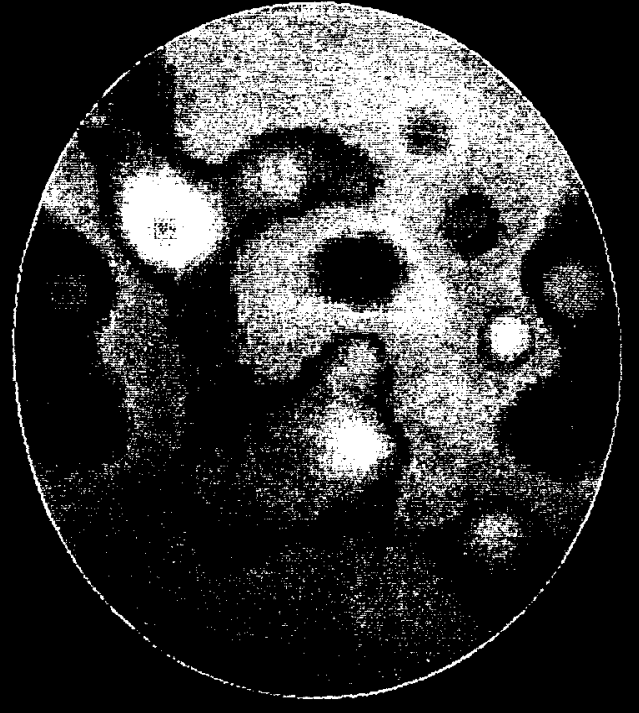

2.50

\section{ats}

0

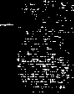

Fig. 4. 1-Values for differences between extraverts and introverts displayed as cortex map. Interpolation method described in text. Colours at the high end of the colour scale indicate areas of higher flow in extraverts (positive $t$-values). Frontal areas are at the top of the map.

Fig. 5. Display of $t$-values associated with the regression coefficient for extraversion in multiple regression equations, where age, sex and extraversion predicted regional blood flow. Display method as in previous picture. 

Håkansson \& Risberg, 1980). On balance, the measurement condition can be described as neither soporific nor highly arousing for the typical $S$. Furthermore, the arousal differences posited by the Eysenck theory must hold over a broad spectrum of conditions if they are to have the pervasive influence on behaviour in daily life that the theory proposes.

The results of the averaged activation measurement indicate that heightened alertness, imposed by mental activation tasks, do not alter the relation between extraversion and flow level. In comparison to the large inter-individual variability in mean $\mathrm{CBF}$, whatever its causes, the intraindividual variability caused by alterations in alertness is very small.

\section{Regional pattern}

The regional differences that constitute the positive findings of this study are compatible with current hypotheses about cortical functions. The frontal and the temporal lobes are the cortical areas most likely to participate in emotional processes underlying personality differences. Of these, the temporal lobes showed bilaterally higher activity in introverts. In the averaged activation measurement, the anterior temporal lobes remained significantly more activated in introverts, although, not surprisingly, at a lower significance level, since the averaging of diverse activation patterns will raise within-group variability and blur between-group regional differences. In the resting measurement, a tendency toward higher left frontal activation in extraverts than in introverts, centered approximately on the area of Broca, suggests the development of an inner monologue in the absence of external stimulation, possibly as an antidote to the boredom of the measurement situation, as suggested by Gale in his discussion of EEG studies (Gale, 1983).

The temporal lobes, beside their suggested role in sensory analysis and memory retrieval, play an important part in emotion, for which their close connections to the limbic system, through the amygdalae and the hippocampi, provide an anatomical foundation. It has been observed by Penfield and his coworkers that direct stimulation of the anterior and medial temporal lobes in conscious humans produces feelings of fear (Penfield \& Jasper, 1959). In a PET study of anticipatory anxiety, Reiman and associates (Reiman, Fusselman, Fox \& Raichle, 1989) found bilateral flow increases in the anterior temporal lobes to characterize a state of anticipation of a painful electric shock. Hagstadius (1990) showed higher flows in basal fronto-temporal areas in high trait anxious $S$ s compared to low anxious.

Direct stimulation of the temporal poles in non-human primates produces a state of behavioural inhibition, hypervigilance and facial expressions indicating "arousal, attention ... or anxiety" (Kaada, 1960). Lesions, on the other hand, of either amygdala or temporal cortex decrease emotionality in general, and release exploratory behaviour from the constraints normally imposed by fear-provoking stimuli (Horel, Keating \& Misantone, 1975). As proposed by Geschwind (1965), and demonstrated by Jones and Mishkin (1972), a system consisting of the amygdala, the temporal lobe, and their connections, are crucial for the association of visually perceived objects with emotional significance.

Clinical observations on patients with temporal lobe damage fall into two broad categories. The Klüver-Bucy syndrome, on the one hand, results from lesions to the amygdala and the temporal lobe, and is characterized by flatness of affect, especially loss of fear, and indiscriminateness in eating and sexual behaviours (Lilly, Cummings, Benson \& Frankel, 1983). Temporal lobe epilepsy, on the other hand, is often accompanied by intensified emotionality, including occasional aggressive outbursts, deepened religious and philosophical interests, moralism and humourlessness, preoccupation with abstract notions of guilt and justice, obsessional and compulsive behaviour, perseveration and circumstantiality in social contacts, and often by hyposexuality (Bear, 1979).

The glaring contrasts between the symptoms of the Klüver-Bucy syndrome and the personality changes in temporal lobe epileptics have invited attempts to explain the latter as caused by something beyond simple tissue damage in the temporal lobes. Bear (1979) has proposed that extended periods of abnormal electrical activity, even when not causing seizures, may lower the thresholds for transmission between the neocortical temporal lobes and the limbic system, especially the amygdala, through the mechanism of kindling (Goddard, Dragunow, Maru \& Macleod, 1986). The consequent sensory-limbic hyperconnectivity tends to imbue sensory information with highly charged emotional significance. As a result of affective over-generalization, previously neutral details may acquire a profound symbolic importance, argues Bear. 
In extension of Bear's hypothesis of cortico-limbic connectivity, the gap between the extremes of the Klüver-Bucy syndrome and temporal lobe epilepsy may be bridged by a middle ground of normal personality variation. The axis along which this variation is arranged may well be extraversion-introversion, or, as will be argued below, Gray's anxiety dimension. Anxiety proneness is higher in introverts, and so is the affinity for obsessive-compulsive disorders if introversion is combined with high neuroticism (Eysenck, 1967). Abstract and theoretical interests characterize introverts more often than extraverts (Bendig, 1963), as well as conscientious and persistent work habits (Eysenck, 1971). Introverts are better at receiving and interpreting non-verbal emotional messages from others (Cunningham, 1977), although extraverts fare better at the transmitting end. Humour with a frivolous content amuses introverts less (Eysenck \& Wilson, 1979). Conversely, lack of behavioural inhibition and free exploration of different sources of drive satisfaction are more often found in extraverts (Wilson, 1981).

Gray (1972) has proposed a rotation of the axes in Eysenck's original 2-dimensional theory to coincide with trait anxiety and impulsivity, an orientation that better reflects the true causal influences, according to this view (Gray, 1982). A dimension of cortico-limbic connectivity, as reflected by temporal activity, would probably correspond more closely to the anxiety dimension than to original introversion-extraversion, considering that many of the characteristics assumed to follow from hyperconnectivity indicate an admixture of introversion and neuroticism. It is worth noting that the proposed anatomical substrate of Gray's anxiety dimension - the septo-hippocampal system-receives a major part of its neocortical input from the temporal lobes.

Tucker and Williamson (1984) have distinguished two self-regulating neural systems, controlling different aspects of brain activity. One--the activation system - controls motor readiness, favours vigilance, and affects cognitive processing toward serial operation and informational redundancy. The other-the arousal system-regulates phasic responses to perceptual input, favours orienting to novel stimuli, habituates easily and facilitates parallel processing.* Tucker and Williamson observe that regulation by activation is often found in introverts, and that the emotional concomitant of this mode of operation is anxiety. Analogously, operation by arousal may be associated with sensation seeking and extraversion.

Identifying, as Bear (1983) does, a phasic arousal system with dorsal, mainly parietal pathways, and a tonic, emotional response system with ventral, mainly temporal pathways, may generate testable hypotheses about differences in cortical subsystems in personality groups. The findings of this study are fully compatible with hypotheses generated by this line of reasoning. Hopefully, progress along these lines may resolve some of the persistent difficulties in demonstrating the general, cortico-reticular arousal differences on which the theory of extraversion-introversion presently relies.

Acknowledgements - This study was supported by grants from the Bank of Sweden Tercentenary Foundation (84/215), the Swedish Medical Research Council (4969) and the Swedish Council for Research in the Humanities and Social Sciences. We are also indebted to Professor David H. Ingvar for valuable comments.

\section{REFERENCES}

Barratt, E. S. \& Patton, J. H. (1983). Impulsivity: Cognitive, behavioral and psychophysiological correlates. In Zuckerman, M. (Ed.), Biological bases of sensation seeking, impulsivity and anxiety. Hillsdale, N.J.: LEA.

Bear, D. M. (1979). Temporal lobe epilepsy-a syndrome of sensory-limbic hyperconnection. Cortex, 15, 357-384.

Bear. D. (1983). Hemispheric specialization and the neurology of emotion. Archives of Neurology. 40, 195-202.

Bendig. A. W. (1963). The relation of temperamental traits of social extraversion and emotionality to vocational interests Journal of General Psychology, 69, 311-318.

Cunningham, M. R. (1977). Personality and the structure of non-verbal communication of emotion. Journal of Personality, 45, 564-584.

Eysenck, H. J. (1967). The biological basis of personality. Springfield, Ill.: Thomas.

Eysenck, H. J. (1971). Readings in extraversion-introversion II. Fields of application. London: Staples.

Eysenck. H. J. (1983). Psychophysiology and personality: Extraversion, neuroticism and psychoticism. In Gale \& Edwards (Eds), Physiological correlates of human behaviour, III (pp. 13-43). London: Academic Press.

Eysenck, H.J. \& Wilson. G. D. (1979). The psychology of sex. London, Dent.

Fuster, J. M. \& Uyeda, A. A. (1962). Facilitation of tachistoscopic performance by stimulation of midbrain tegmental points in the monkey. Experimental Neurologi, 6, 384-406.

*The terms activation and arousal are not to be confused with the different sense in which Eysenck uses them in his 1967 theory. 
Gale, A. (1983). Electroencephalographic studies of extraversion-introversion: A case study in the psychophysiology of individual differences. Personality and Individual Differences, 4, 371-380.

Geschwind, N. (1965). Disconnexion syndromes in animals and man. Part I. Brain, 88, 237-294.

Goddard, G. V., Dragunow, M., Maru, E. \& Macleod, E. K. (1986). Kindling and the forces that oppose it. In Doane, B. K. \& Livingston, K. E. (Ed.), The Limbic System: Functional organization and clinical disorders. New York: Raven Press.

Gray, J. A. (1972). The psychophysiological nature of introversion-extraversion: A modification of Eysenck's theory. In Nebylitsyn, V. D. \& Gray, J. A. (Ed.), Biological bases of individual behavior (pp. 182-205). London: Academic Press.

Gray, J. A. (1982). The neuropsychology of unxiety. An enquiry into the functions of the septo-hippocampal system. Oxford: Oxford University Press.

Gur, R. C., Gur, R. E., Skolnick, B. E., Resnick, S. M., Silver, F. L., Chawluk, J., Muenz, L., Obrist, W. D. \& Reivich, M. (1988). Effects of task difficulty on regional cerebral blood flow: Relationships with anxiety and performance. Psychophysiology, 25, 392-399.

Hagstadius, S. (1990). Anxiety proneness related to the regional cerebral blood flow during resting and mental activation. Submitted for publication.

Hagstadius, S. \& Risberg, J. (1989). Regional cerebral blood flow characteristics and variations with age in resting normal subjects. Brain and Cognition, 10, 28-43.

Horel, J. A., Keating, E. G. \& Misantone, L. J. (1975). Partial Klüver-Bucy syndrome produced by destroying temporal neocortex or amygdala. Brain Research, 94, 347-359.

Ingvar, D. H. (1985). Memory of the future: An essay on the temporal organization of conscious awareness. Human Neurobiology, 4, 127-136.

Ingvar. D. H. \& Risberg, J. (1965). Influence of mental activity upon regional cerebral blood flow in man. Acta Neurologica Scandinavica, 41 (Suppl. 14), 93-96.

Ingvar, D. H. \& Risberg, J. (1967). Increase of regional cerebral blood flow during mental effort in normals and in patients with focal brain disorders. Experimental Brain Research, 3, 195-211.

Jones, B. \& Mishkin, M. (1972). Limbic lesions and the problems of stimulus-reinforcement associations. Experimental Neurology, 36, 362-377.

Kaada, B. R. (1960. Neurophysiology. In Field, J. \& Magoun, H. W. (Ed.), Handbook of Physiology (pp. 1345-1372). Washington, D.C.: American Physiological Society.

Levery, A. B. \& Martin, I. (1981). Personality and conditioning. In Eysenck, H. J. (Ed.), A model for personality (pp. 123-168). Berlin: Springer.

Lilly, R., Cummings, J. L., Benson. F. \& Frankel, K. (1983). The human Klüver-Bucy syndrome. Neurology, 33, $1141-1145$.

Mathew, R.J., Weinman, M. L. \& Barr, D. L. (1984). Personality and regional cerebral blood flow. British Journal of Psychiatry, 144, 529-532.

Maximilian, V. A., Prohovnik, I. \& Risberg, J. (1980). Cerebral hemodynamic response to mental activation in normoand hypercapnia. Stroke, $111,342-347$

Obrist, W. D., Thompson, H. K., Wang. H. S. \& Wilkinson, W. E. (1975). Regional cerebral blood flow estimated by 133-xenon inhalation. Stroke, 6, 245-256.

O'Gorman. J. G. (1984). Extraversion and the EEG: I. An evaluation of Gale's hypothesis. Biological Psychologi, 19, 95-112.

O'Gorman, J. G. \& Mallise, L. R. (1984). Extraversion and the EEG: II. A test of Gale's hypothesis. Biological Psychology, 19. 113-127.

Penfield, W. \& Jasper, H. H. (1959). Epilepsy and the functional anatomy of the human brain. Boston: Little Brown.

Prohovnik, I. Håkansson, K. \& Risberg. J. (1980). Observations on the functional significance of regional cerebral blood flow in 'resting' normal subjects. Neuropsychologia, 18, 203-217.

Raichle, M. E., Grubb, R. L., Gado, M. H.. Eichling. J. O. \& Ter-Pogossian, M. M. (1976). Correlation between regional cerebral blood flow and oxidative metabolism. Archives of Neurology, 33, 523-526.

Reiman, E. M., Fusselman, M. J.. Fox, P. T. \& Raichle, M. E. (1989). Neuroanatomical correlates of anticipatory anxiety. Science, 243, 1071-1074.

Revelle, W., Humphreys, M. S., Simon, L. \& Gilliland, K. (1980). The interactive effect of personality, time of day, and caffeine: a test of the arousal model. Journal of Experimental Psychology: General, 109, 1-31.

Risberg. J. (1980). Regional cerebral blood flow measurements by $133 \mathrm{Xe-inhalation:} \mathrm{Methodology} \mathrm{and} \mathrm{applications} \mathrm{in}$ neuropsychology and psychiatry. Brain and Language, 9, 9-34.

Risberg, J. (1986). Regional cerebral blood flow. In Hannay, J. (Ed.), Experimental techniques in human neuropsychology (pp. 514-543). Oxford: Oxford University Press.

Risberg, J. \& Ingvar, D. H. (1973). Patterns of activation in the grey matter of the dominant hemisphere during memorization and reasoning. Brain, 96, 737-756.

Rodriguez, G., Warkentin. S., Risberg, J. \& Rosadini, G. (1988). Sex differences in regional blood flow. Journal of Cerebral Blood Flow and Metabolism, 8, 783-789.

Schalling, D., Edman, G. \& Åsberg, M. (1983). Impulse cognitive style and inability to tolerate boredom: Psychobiological studies of temperamental vulnerability. In Zuckerman, M. (Ed.), Biological bases of sensation-seeking, impulsivity and anxiety. Hillsdale, N.J.: Eribaum.

Siddle, D. A., Morrish, R. B.. White, K. D. \& Mangan, G. L. (1969). Relation of visual sensitivity to extraversion. Journal of Experimental Research in Personality, 3, 264-267.

Stelmack. R. M. (1981). The psychophysiology of extraversion and neuroticism. In Eysenck, H. J. (Ed.), A model for personality (pp. 38-64). Berlin: Springer.

Stelmack. R. M. \& Campbell. K. B. (1974). Extraversion and auditory sensitivity to high and low frequency. Perceptual and Motor Skills, 38, 875-879.

Tucker, D. M. \& Williamson, P. A. (1984). Asymmetric neural control in human self-regulation. Psychological Review, 91, $185-215$.

Vasey, M. W. \& Thayer, J. F. (1987). The continuing problem of false positives in repeated measures ANOVA in psychophysiology: A multivariate solution. Psychophysiology, 24, 479-486.

Wilson. G. D. (1981). Personality and social behaviour. In Eysenck, H. J. (Ed.), A model for personality. Berlin: Springer. 